\title{
"Short report" staffing in practice: five years' experience of a consultant based service in obstetrics and neonatal paediatrics
}

\author{
M J Hare, R N Miles, C R Lattimore, J P Southern
}

\begin{abstract}
Recent government plans include the concept of a core of doctors of intermediate grade providing 24 hour emergency cover in hospital departments. Hinchingbrooke Hospital has, since its opening in 1983 , been run on a two tier basis, with consultants and a part time senior registrar supported only by senior house officers in their first post, usually on general practice vocational training schemes. With a planned rate of around $\mathbf{2 0 0 0}$ deliveries per year all high risk obstetric and neonatal paediatric procedures, including ventilation of very small babies, have been carried out within the hospital. A study of the first five complete years of operation of the obstetric and paediatric departments showed that the perinatal mortality rate was low (hospital rate $4 \cdot 7 / 1000$ in 9149 deliveries during $1984-8 v$ district rate $5 \cdot 1 / 1000$ during $1986-8$ ), and patient satisfaction seemed to be high. In a separate prospective study of out of hours work performed by consultants in paediatrics (four weeks) and obstetrics ( 20 days) three consultants in paediatrics spent 71 hours working out of hours; for the obstetricians, of the $\mathbf{5 6}$ requests for advice and 38 interventions, only five and six respectively occurred between midnight and 9 am.

Although successful at this hospital, the two tier system would be expensive under the Royal College of Obstetricians' guidelines of one consultant to a maximum of $\mathbf{5 0 0}$ deliveries. An equal mixture of two tier and three tier systems might be the best solution for patient care and training of junior doctors.
\end{abstract}

\section{Introduction}

Over the past decade there has been much debate about a suitable staffing structure for hospital doctors and the apparent incompatibility between perceived service needs and an acceptable career structure. Although there is general acceptance that in future more emergency work will need to be performed by consultants rather than consultant trainees, there is no agreement about how this should be arranged or how quickly change should occur. In its report in 1980 the House of Commons Social Services Committee seemed to suggest a rapid increase in the consultant grade in obstetrics and gynaecology and supported the idea that patient care throughout the NHS should be given largely by fully trained doctors in career posts.' If this was taken to suggest a consultant based service rather than a consultant led one the idea was firmly rejected by fellows and members of the Royal College of Obstetricians and Gynaecologists. ${ }^{2}$ The more recent government planning document Achieving a Balance ${ }^{3}$ introduces the concept of the "safety net," usually interpreted as a core of experienced intermediate grade doctors of sufficient numbers in each department to provide a full 24 hour service for managing common emergencies.
Hinchingbrooke Hospital opened in late 1983 as a new hospital in a new health district, and as such it did not inherit an entitlement to registrar posts. The consultant staff in obstetrics and paediatrics appointed to the district for the opening of the service agreed that it should be run on a two tier system, with inexperienced senior house officers destined for careers in general practice as the only junior staff. This report covers the first five complete years of operation of the unit.

\section{Subjects and methods}

The Huntingdon health district was formed in 1982 by division of the then Cambridge Area and District Health Authorities. Its permanent resident population was 112000 (135000 in 1988), swollen by about 10000 by servicemen and their dependants from the RAF and the United States Air Force. The total number of women having babies within the district rose from 1689 in 1984 to 1934 in 1988.

The maternity and paediatric services are based at this hospital, a newly built unit on the "best buy" pattern. In obstetrics and gynaecology four full time or maximum part time consultants share the workload. Initially, they were supported by three senior house officers, but from 1986 a fourth was made available on secondment from the British army. All the senior house officers are preparing for careers in general practice; two posts form part of the vocational training scheme for general practice within the health district. The paediatric department is staffed by two full time consultants and one part time senior registrar employed on a married woman's training scheme. This last post was closed in 1989, when the holder was appointed to a newly created part time consultant post at this hospital. There are three senior house officers, all planning careers in general practice; two posts form part of the general practice vocational training scheme.

From the outset the hospital tried to provide a full obstetric and neonatal service and to include the management of all high risk pregnancies within the district and the intensive care (including ventilation) of very small babies. We analysed its performance during 1984-8 with data from internal audit procedures and data collected by the Office of Population Censuses and Surveys.

\section{Results}

Table I shows data for 1984-8 inclusive, the first five years of operation, during which just over 9000 women were delivered. Table II shows the matching data for Huntingdon health district. ${ }^{4}$ Up to 1987 there was a net loss of women moving out of the district to have their babies. With the exception of 1984, the year the unit opened, when many women were already booked into other hospitals, the loss was accounted for by 
American women choosing to give birth in a United States Air Force hospital located in a different health district; such women numbered about 75 a year. In 1987 the number of women giving birth in Hinchingbrooke Hospital exceeded the total for the district by 67 , indicating that about 140 British women from other areas travelled to Huntingdon to have their babies, and this continued in 1988.

The aim of the paediatric staff has been to provide a comprehensive neonatal service. From 1985 almost all babies with low birth weight born at this hospital and requiring ventilation were managed here. In 1986 and 1987 two babies were transferred for ventilation after delivery when the intensive care facilities at the hospital were already occupied. Between two and five babies were transferred for specialist surgery in each year within and outside the East Anglian region. About two in utero transfers occurred in each year when intensive care cots at the hospital were occupied.

Table III shows the results of the special and intensive care of 183 babies with low birth weight $(<2000 \mathrm{~g})$ born without lethal congenital abnormalities at the hospital between 1984 and 1988. Of these, 172 $(94 \%)$ survived the neonatal period; four are known to have died later, two from causes unrelated to their prematurity. Outcome was assessed by follow up of all babies weighing $<2000 \mathrm{~g}$ at birth. Among the 168 babies surviving, appreciable neurological impairment has so far been identified in $10(6 \%)$ : three children have severe problems, with spastic quadriplegia and mental handicap; six have mild to moderate problems, with cerebral diplegia; and one has hydrocephalus with a shunt but no apparent neurological deficit. Like others, we have noted a short attention span in a few toddlers with no other problems, and only longer term follow up will show whether this is important.

\section{Discussion}

The traditional medical structure in major hospital specialties in the United Kingdom is three tiered, with a consultant supported by a doctor at intermediate level (registrar) and one at junior level (senior house officer). Although few neonatal paediatric units expect to achieve this pattern, most obstetric services aspire to it. Three tier working with registrars, however, is a myth rather than a reality for most units: according to the Royal College of Obstetricians and Gynaecologists

TABLE I-Deliveries, outcome, and perinatal mortality rate at Hinchingbrooke Hospital, 1984-8

\begin{tabular}{|c|c|c|c|c|c|c|}
\hline & 1984 & 1985 & 1986 & 1987 & 1988 & Total \\
\hline Total No of women delivered & 1482 & 1742 & 1784 & 2027 & 2114 & 9149 \\
\hline \multicolumn{7}{|l|}{ Type of delivery: } \\
\hline Spontaneous cephalic delivery (single) & 1143 & 1365 & 1427 & 1603 & -1607 & $7145(78 \%)$ \\
\hline Forceps or ventouse & 112 & 93 & 79 & 103 & 145 & $532(5 \cdot 8 \%)$ \\
\hline Caesarean section & 204 & 248 & 250 & 266 & 284 & $1252(13 \cdot 7 \%)$ \\
\hline \multicolumn{7}{|l|}{ Deaths: } \\
\hline Stillbirth & 5 & 4 & 7 & 5 & 4 & 25 \\
\hline Death of infant in first week & 2 & 8 & 4 & 1 & 3 & 18 \\
\hline Neonatal death & 6 & 8 & 4 & 2 & 5 & 25 \\
\hline Lethal malformations & 1 & 4 & 3 & 1 & 4 & 13 \\
\hline Perinatal mortality rate (per 1000) & $4 \cdot 7$ & 6.9 & $6 \cdot 1$ & $2 \cdot 9$ & $3 \cdot 4$ & $4 \cdot 7$ \\
\hline Corrected perinatal mortality rate (per 1000 ) & $4 \cdot 0$ & $3 \cdot 4$ & 4.5 & $2 \cdot 5$ & $1 \cdot 4$ & $3 \cdot 3$ \\
\hline
\end{tabular}

TABLE II - Live births, stillbirths, perinatal mortality rate, and infant mortality in women in Huntingdon health district according to Office of Population Censuses and Surveys, 1984-8

\begin{tabular}{lcccccc}
\hline & 1984 & 1985 & 1986 & 1987 & 1988 & $1986-8^{\star}$ \\
\hline Live births & 1689 & 1811 & 1800 & 1941 & 1934 & \\
Deaths: & $12(7 \cdot 1)$ & $17(9 \cdot 4)$ & $10(5 \cdot 6)$ & $10(5 \cdot 2)$ & $8(4 \cdot 1)$ & $5 \cdot 1$ \\
$\quad<1$ Year (per 1000) & 4 & 8 & 7 & 3 & 5 & \\
$<4$ Weeks & 2 & 8 & 6 & 1 & 3 & \\
$<$ < Week & 8 & 5 & 8 & 5 & 6 & \\
Stillbirths & $5 \cdot 9$ & $7 \cdot 2$ & $7 \cdot 7$ & $3 \cdot 1$ & $4 \cdot 6$ & $5 \cdot 1$ \\
Perinatal mortality rate (per 1000) & $7 \cdot 1$ & $6 \cdot 8$ & $7 \cdot 3$ & $6 \cdot 3$ & $6 \cdot 3$ & \\
Birth weight <2500 g $(\%)$ & & &
\end{tabular}

*For 1986-8 the perinatal mortality rate and infant mortality were the lowest for any health district in England and Wales."
TABLE III - Outcome (corrected for lethal congenital abnormalities) in 183 liveborn babies with low birth weight at Hinchingbrooke Hospital, 1984-8

\begin{tabular}{lccc}
\hline & \multicolumn{2}{c}{ Outcome } & \\
\cline { 2 - 3 } Birth weight & Live born & Died & \% Survival \\
\hline$<1000 \mathrm{~g}$ & 20 & 6 & 70 \\
$1000-1499 \mathrm{~g}$ & 43 & 4 & 91 \\
$1500-1999 \mathrm{~g}$ & 120 & 1 & 99 \\
\hline
\end{tabular}

only $22.9 \%$ of such units have the three or more registrars needed to provide complete emergency cover; $40 \%$ have one registrar or none.

Some units switch from two to three tier working on a day to day basis depending on the availability of staff. ${ }^{\circ}$ Others maintain a three tier structure by employing senior house officers at two levels, with one at basic level reporting to another with more experience. This structure is unofficial and carries no financial differential, but a recent survey of advertisements in the $B M F$ suggests that about a fifth of senior house officer posts are intended to cover registrar duties. One hospital clearly worked a system with three tiers of senior house officers.

At this hospital a decision was made to adopt the two tier structure, with inexperienced senior house officers working directly under consultants. This inevitably required reassessment and readjustment of traditional working patterns, duties, and responsibilities. For example, in the labour ward the final responsibility for deciding to notify the duty consultant of a problem rests with the senior midwife on duty and not with the senior house officer, although the junior doctor would be expected to be aware of the problem and to contribute to the decision making process. In general, midwives are expected to increase their clinical rolefor example, taking responsibility for forewater rupture, setting up intravenous infusions, enhancement of labour, and repairing perineal damage. The working patterns that have evolved have been discussed by Green et al and Coupland et al. ${ }^{8}$

In most neonatal units providing intensive care a three tier system or at least employment of senior house officers with previous paediatric experience is usual. At this hospital, which has inexperienced junior resident staff, much neonatal resuscitation and intensive care is carried out by the consultants, but we believe that this results in consistently good care and good outcome.

Figures for perinatal and neonatal survival at this hospital compare favourably with those in studies from other neonatal intensive care units. For example, babies $<1500 \mathrm{~g}$ born in the Leeds unit between 1983 and 1985 had an $86 \%$ survival, ${ }^{4}$ and babies $<2001 \mathrm{~g}$ born in the Manchester unit between 1976 and 1980 had a $78 \%$ survival. ${ }^{10}$ The mortality for infants with very low birth weight $(<1500 \mathrm{~g})$ in the Mersey region in 1983 was $25 \%,{ }^{11}$ ranging from $100 \%$ for infants with a birth weight $<700 \mathrm{~g}$ to $10 \%$ in those with a birth weight in the range $1400-1499 \mathrm{~g}$.

Direct comparison of morbidity with other reported studies is difficult as each study defines disability slightly differently. Seventy one $(6 \cdot 8 \%)$ of 1048 survivors in a geographically defined population of infants with low birth weight $(<2000 \mathrm{~g})$ in the Mersey region had a total of 113 neurological impairments. ${ }^{12}$ Of 490 babies born in the North West Regional Perinatal Centre, Manchester, between 1976 and 1980, 35 (7\%) were considered to have a major handicap." The incidence of a handicap was higher in antenatal referrals (9\%) and neonatal referrals (14\%). A more recent study of outcome in neonatal survivors born in the Northern region in 1983 related outcome to gestation rather than birth weight ${ }^{13} ; 18(8 \%)$ of 212 long term survivors who weighed $<1500 \mathrm{~g}$ at birth were con- 
sidered to be severely disabled. Several studies have confirmed that outcome is not improved by neonatal transfer to regional intensive care units, ${ }^{114}$ and a careful comparison of outcomes showed no demonstrable advantage of antenatal transfer to a regional centre."

The unit at this hospital is also popular, as witnessed by reports in local and national consumer publications. This is at least in part due to the freedom and encouragement given to women to plan their own labour, an arrangement that is easier to demonstrate in a labour ward run by midwives rather than doctors. It is difficult to assess how many women do play a part in planning their labour, but probably it is most. About a third of those women who deliver spontaneously do so in positions other than lying on their backs.

To assess the amount of out of hours work (especially night work) each department performed a separate prospective survey. Over four weeks the three paediatric consultants spent among them 71 hours above normal working requirements in clinical work within the hospital. At the time one of the senior house officers was very experienced but the two others were new to paediatrics. Comparable figures cannot be produced for the obstetric consultants as the period studied coincided with a vacant post and the use of locum consultant cover; also, one of the permanent consultants is voluntarily resident when on call. Twenty days of consultant cover in obstetrics and gynaecology were, however, analysed in depth. There were 56 requests for advice, and 38 interventions (deliveries, operations, etc) were performed. Most were during normal working hours $(45$ requests for advice and 25 interventions) or between $6 \mathrm{pm}$ and midnight (16 requests for advice and seven interventions); only five requests for advice and six interventions were recorded between midnight and $9 \mathrm{am}$.

The two tier system practised at this hospital is not necessarily the ideal blueprint for all: "career" junior doctors must be trained, and night work becomes more onerous as consultants become older. The system will also be expensive to run if the Royal College of Obstetricians and Gynaecologists' guideline of one consultant to no more than 500 deliveries is to be followed, and, certainly, the Huntingdon health district is committed to increasing consultant numbers in obstetrics and paediatrics. Nevertheless, the night work is no heavier than that performed by some consultants in the three tier units. ${ }^{67}$ With regard to the need to train juniors, in obstetrics over $70 \%$ of registrars and $60 \%$ of "career" senior house officers are from overseas and do not look to obtain consultant posts here. ${ }^{2}$ However strong our feeling of obligation to train overseas doctors, especially from Commonwealth countries, it should not be forgotten that in many, perhaps most, developed countries emergency care is given or supervised directly by fully trained staff ${ }^{5}$ and that recent reports on perioperative deaths ${ }^{16}$ and maternal mortality ${ }^{17}$ suggest that juniors are often working beyond their capabilities. A half and half mixture of two tier and three tier units might be the best solution, with doctors encouraged to consider a move at the midpoint of their consultant career. Such a system would seem to provide the best answer to patient care and the training of future specialists.

We are indebted to Dr Jill Challener, consultant paediatrician, and Miss Isobel Milner, senior labour ward midwife, for statistical help.

\footnotetext{
1 Social Services Committee. Perinatal and neonatal mortality. Second report from the House of Commons Social Services Committee Session 1979-80. London: HMSO), 1980

2 Manpower Advisory Subcommittee, Roval College of Obstetricians and Gynaccologists. Report. London: RCOG, 1983.

3 Department of Health and Joint Consultants Committee. Hospital medical staffing: achieving a balance. London: HMSO, 1986.
}

+ Office of Population Censuses and Surveys. Infant and perinatal mortality 1988: district health authorities. Series DH3. London: HMSO, 1989.

5 Green JM, Coupland VA, Kitzinger JV, Harvey JD, Hare MJ. Observations on obstetric staffing: the myth of the three-tier norm. $\mathcal{F}$ Obstet Gynaecol 1989;9:289-92.

6 McGarry J. Hour log shows extent of seniors' burden. Hospital Doctor 1989;9:18

7 Green JM, Kitzinger JV, Coupland VA. The division of labour. Cambridge: Child Care and Development Group, University of Cambridge, 1986.

8 Coupland VA, Green JM, Kitzinger JV, Richards MPM. Obstetricians on the labour ward: implications of medical staffing structure. Br Med 7 1987;295: labour

9 Beverley D, Foote K, Howel D, Congdon P. Effect of hirthplace on infants with low birth weight. Br Med f 1986;293:981-3.

10 Marlow N, Chiswick ML. Neurodevelopmental outcome of babies weighin less than $2001 \mathrm{~g}$ at birth: influence of perinatal transfer and mechanical ventilation. Arch Dis Child 1988;63:1069-74.

11 Sandhu B, Stevenson RC, Cooke RWI, Pharaoh POD. Cost of neonatal intensive care for very low birthweight infants. Lancet 1986; i:600-3.

12 Powell TG, Pharaoh POD, Cooke RWI. Survival and morbidity in geographically defined population of low birthweight infants. Lancet 1986;i:539-43.

13 Warivar U, Richmond S, Hey E. Pregnancy outcome at 24-31 weeks' gestation: neonatal survivors. Arch Dis Child 1989;64:678-86.

14 Marlow N, Hunt LP. Chiswick M. Clinical factors associated with adverse outcome for babies weighing $2000 \mathrm{~g}$ or less at birth. Arch Dis Child 1988;63:1131-6.

15 Kochli N. Junior doctors' hours. Br Med f 1989;298:1523.

16 Buck N, Devlin HB, Lunn JN. Confidential enquiry into perioperative deaths. London: Nuffield Provincial Hospital Trust, 1987.

17 Turnbull A, Tindall VR, Beard RW, et al. Report on confidential enquiries into maternal deaths in England and Wales 1982-1984. London: HMSO, 1989.

(Accepted 19 fanuary 1990)

\section{Update box for Oxford Handbook of Clinical Medicine (2nd ed), p 429}

\section{Blepharospasm}

Blepharospasm is the repetitive, involuntary contraction of the orbicularis oculi muscle. It is one of the focal dystonias and may make the patient effectively blind. If the condition is not recognised it is all too easy to dismiss patients as histrionic and to think that they are screwing up their eyes deliberately-especially as the more a sceptical doctor questions and probes an afflicted patient the worse the blepharospasm may become (stress is an important exacerbating factor).

Clinical features: The ratio of women to men with blepharospasm is $1 \cdot 8$. Blepharospasm is often preceded by exaggerated blinking. Other dystonias may be present-for example, oromandibular dystonia. It usually starts unilaterally, becoming bilateral. Patients may develop various tricks to overcome or reduce their blepharospasm such as touching or pulling the eyelids-a variation of "geste antagoniste" seen in other forms of dystonia.

Causes: Mostly unknown. Recognised antecedent events are treatment with neuroleptic drugs, Parkinson's disease, and progressive supranuclear palsy.

Drug treatment: There are no panaceas and the response to drugs is variable, with beneficial effects tending to wear off with time. Most helpful are anticholinergics such as benzhexol given, for example, orally at a dose of $1 \mathrm{mg} /$ day, which is gradually increased up to $5 \mathrm{mg} / 8 \mathrm{~h}$ (tablets are $2 \mathrm{mg}$ or $5 \mathrm{mg}$ ). Dopamine agonists (levodopa, bromocriptine) or antagonists may help.

Treatment with botulinum toxin: In this new approach palliation is achieved with nanogram doses of this neurotoxin given to the orbicularis oculi muscle, in which it produces a temporary flaccid paralysis. It can help some people recover effective vision.' It binds to peripheral nerve terminals and inhibits the release of acetylcholine. Treatment may need to be repeated - for example, every three months

Supportive treatment: Patients may gain considerable support from the Dystonia Society, Unit 23, Omnibus Workplace, 39-41 North Road, London N7 9DP (tel: $017004594)$. - J M LONGMORE

1 Grandas F, Elston J, Quinn N, Marsden CD). Blepharospasm: a review of 264 patients. F Neurol Neurosurgery Psvchiatry 1988;51:767-72.

Anybody may submit an update box; all boxes are peer reviewed 